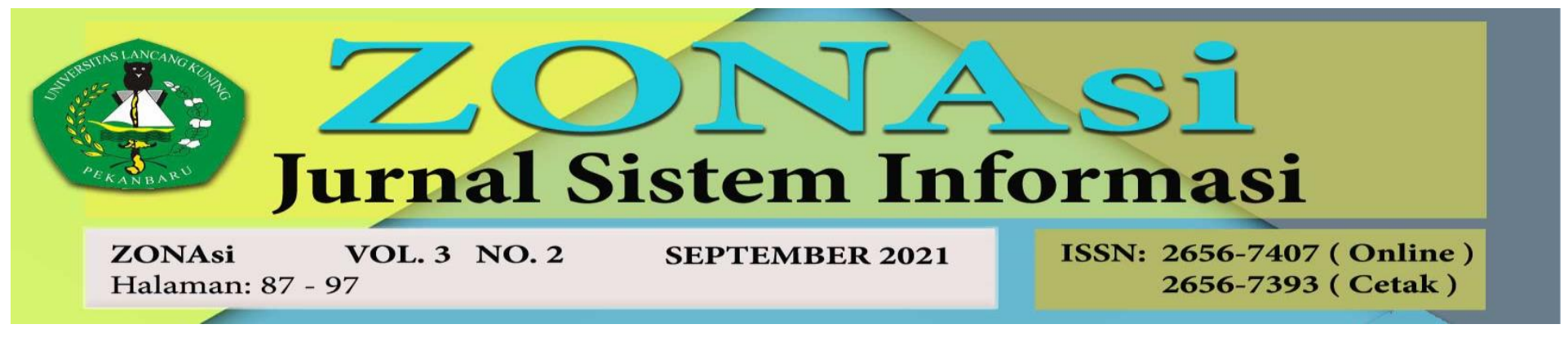

\title{
PEMBUATAN PROSES BISNIS DAN STANDAR OPERASIONAL PROSEDUR PADA DINAS PEMUDA, OLAHRAGA DAN PARIWISATA KOTA BALIKPAPAN
}

\author{
Samuel Govery $^{1}$, Yuyun Tri Wiranti ${ }^{2}$, Sri Rahayu Natasia ${ }^{3}$ \\ ${ }_{1,2,3}$ Institut Teknlogi Kalimantan \\ (Program Studi Sistem Informasi Jurusan Matematika dan Teknologi Informasi \\ (Institut Teknologi Kalimantan) \\ (Jl. Sungai Wain KM. 15 Karang Joang, Balikpapan Utara, Balikpapan, Kal-Tim) \\ e-mail: $\underline{\text { samuelgovery@gmail.com, }}{ }^{2}$ yuyun@ lecturer.itk.ac.id, ${ }^{3}$ natasia.ayu@ lecturer.itk.ac.id
}

\begin{abstract}
Abstrak
Dinas Pemuda, Olahraga dan Pariwisata (DPOP) Kota Balikpapan memiliki fungsi untuk melaksanakan urusan pemerintahan dalam hal kepemudaan, olahraga dan pariwisata. Sebelumnya, DPOP Kota Balikpapan telah mempunyai 15 dokumen Standar Operasional Prosedur Administrasi Pemerintahan (SOP AP). Namun, SOP yang yang ada tersebut perlu untuk dievaluasi dan disesuaikan dengan keadaan saat ini. DPOP Kota Balikpapan juga tidak mempunyai pemetaan proses bisnis. Sehingga, pada penelitian ini dilakukan pemodelan proses bisnis serta penyusunan SOP AP pada DPOP Kota Balikpapan dengan menggunakan Permenpan RB RI Nomor 19 Tahun 2018 serta Permanpan RB RI Nomor 35 Tahun 2012 sebagai landasannya. Kemudian, digunakan Business Process Model Notation (BPMN) untuk notasi proses bisnisnya dan flowcharts untuk menyusun SOP AP. Dari penelitian ini dihasilkan 15 as-is process yang kemudian dievaluasi dengan value-added analysis sehingga menghasilkan 15 to-be process dan 16 proses yang baru yang belum didokumentasikan, akhirnya diperoleh total proses yang dimodelkan dan disusun ke dalam proses bisnis dan SOP AP adalah 31 proses.
\end{abstract}

Kata kunci: SOP AP, Proses Bisnis, DPOP Kota Balikpapan

\begin{abstract}
The Department of Youth, Sports and Tourism (DPOP) of Balikpapan City has a function to carry out government affairs in terms of youth, sports and tourism. Previously, DPOP of Balikpapan had 15 SOP documents. However, the existing SOPs need to be evaluated and adjusted to the current situation. DPOP of Balikpapan also does not have a business process mapping. Thus, in this study, business process modeling and preparation of AP SOPs at the DPOP of Balikpapan City were carried out using the Ministerial Regulation of the Republic of Indonesia RB Number 19 of 2018 and the Regulation of the Republic of Indonesia RB Number 35 of 2012 as the basis. Then, Business Process Model Notation (BPMN) is used for business process notation and flowcharts to prepare SOPs. From this research, 15 as-is processes were produced which were then evaluated by value-added analysis so as to produce 15 to-be processes and 16 new processes that have not been documented. Finally, the total processes modeled and compiled into business processes and SOPs are 31 process.
\end{abstract}

Keywords: SOP, Business Process, DPOP Of Balikpapan. 


\section{Pendahuluan}

Penyampaian informasi yang baik harus dimiliki oleh setiap perusahaan ataupun instansi. Peyampaian informasi yang baik dapat dicapai dengan koordinasi yang baik pada setiap elemen di instansi tesebut. Hal tersebut dikarenakan dalam suatu intansi terdapat beberapa proses bisnis yang berkaitan satu dan yang lainnya. Proses bisnis yang telah berjalan dengan baik dapat memberikan peningkatan pada kualitas informasi yang ada [1]. Selain itu, penggunaan Standar Operasional Prosedur Administrasi Pemerintahan (SOP AP) juga dibutuhkan pada organisasi untuk menjadi acuan dalam melaksanakan tugas pekerjaan. Seperti yang tertuang pada Peraturan Menteri Pendayagunaan Aparatur Negara dan Reformasi Birokrasi Republik Indonesia (PERMENPAN RB RI) Nomor 35 Tahun 2012 yang berisi serangkaian instruksi tertulis yang dibakukan mengenai berbagai proses penyelenggaraan aktivitas organisasi. Sehingga, SOP menjadi acuan standar kerja digunakan oleh instansi pemerintahan dalam melaksanakan tugasnya [2] [3].

Di samping kebutuhan dokumen SOP, Kementerian Pendayagunaan Aparatur Negara dan Reformasi Birokrasi Republik juga mengeluarkan peraturan menteri terkait dengan proses bisnis yang tertuang pada Peraturan Menteri Pendayagunaan Aparatur Negara dan Reformasi Birokrasi Nomor 19 Tahun 2018 tentang Penyusunan Peta Proses Bisnis Instansi Pemerintahan yang mendorong setiap pemerintah daerah untuk menyusun proses bisnisnya. Hal ini juga merupakan bentuk upaya mencapai visi, misi, dan tujuan organisasinya [4].

Beberapa penelitian sebelumnya yang mendukung penelitian ini adalah yang pertama dari penelitian Sutrisno (2020), yang melakukan penelitian pada Badan Pengelola Pajak Daerah dan retribusi Daerah (BPPDRD) Kota Balikpapan dengan menggunakan BPMN dan flowcharts. Sehingga, dihasilkan 20 to-be processes [5]. Kemudian, penelitian yang dilakukan Dewantari (2018) pada UMKM XYZ yang dilandasi oleh keterlambatan pesanan sehingga dilakukan pendekatan menggunakan BPMN dan analisis kualitatif menggunakan value-added analysis dan dihasilkan 4 proses yang diperbarui [6]. Kemudian, penelitian yang dilakukan oleh Yunitarini, Dkk (2016) karena belum adanya pemodelan proses bisnis pada kegiatan akademik di Teknik Informatika Universitas Trunjoyo menggunakan pendekatan BPM dan notasi BPMN dan dihasilkan 5 proses bisnis akademik [7]. Penggunaan BPMN dan flowcharts juga dilakukan oleh Zakiah (2020) pada Dinas Pendidikan dan Kebudayaan (Disdikbud) Kota Balikpapan dengan menjadikan PERMENPAN RB RI Nomor 35 Tahun 2012 sebagai landasa, sehingga dihasilkan 69 proses bisnis yang dimodelkan [8]. Selanjutnya, adalah penelitian yang dilakukan oleh Kurnawati (2020) tentang pemodelan proses bisnis dan peyusunan SOP Manajamen kerjasama dan beasiswa pada Institut Teknologi Kalimantan dengan menggunakan pendekatan BPM dan dihasilkan 4 proses bisnis pelaksanaan kerja sama dan 8 proses bisnis beasiswa [9]. Dari penelitian-penelitian ini semuanya menggunakan pendekatan BPM dalam memodelkan proses bisnisnya dan menggunakan BPMN sebagai notasinya. Selain itu, satu diantaranya menggunakan analisis kualitatif berupa value-added analysis untuk mengevaluasi proses yang ada. Dan beberapa diantaranya menggunakan flowcharts serta aturan pada PERMENPAN RB RI nomor 35 Tahun 2012 untuk menyusun SOP dari proses yang ada.

Perwujudan dari pelayanan yang trasnparan dan terstandar dapat dinyatakan dengan melakukan penyusunan standar pelayanan untuk setiap jenis layanan yang ada di Dinas Pemuda, Olahraga dan Pariwisata (DPOP) Kota Balikpapan. Untuk mempermudah penyusunannya, maka perlu ditetapkan prosedur dari setiap layanan yang dilaksanakan. Dari prosedur tersebut maka dapat ditetapkan sebuah prosedur baku yang kemudian akan disusun menjadi dokumen SOP. Dari hasil wawancara yang dilakukan dengan Kasubbag. Program dan Keuangan DPOP Kota Balikpapan, DPOP Kota Balikpapan telah memiliki 15 dokumen SOP, seperti SOP Pemilihan Duta Pariwisata, SOP Surat Menyurat, SOP Pembagian Bonus Atlet dan Pelatih, SOP Retribusi Sarana Olahraga, dan lain sebagainya. Namun dokumen SOP yang ada berasal dari tahun 2015 sehingga harus dilakukan perbaruan. Hal ini dikarenakan menurut PERMENPAN RB RI Nomor 35 Tahun 2012 SOP harus dievaluasi setidaknya setahun sekali. Selain itu, DPOP sendiri belum memiliki dokumentasi proses bisnis. Tidak adanya pemetaan proses bisnis dan SOP yang terbaharui membuat pegawai yang ada di DPOP Kota Balikpapan melakukan kegiatan dan 
proses yang ada berdasarkan ingatan dan pengalaman sehingga, dalam pelaksanaannya banyak kegiatan yang terlewat dan harus dilakukan pengulangan sebagaimana mestinya. Kurangnya SDM yang menguasi pemetaan proses bisnis dan evaluasi terhadap SOP menjadi salah satu faktor mengapa penelitian dilakukan. Pemetaan proses bisnis yang dilakukan juga dapat menjadi dasar dalam penyusunan SOP, karena proses yang didokumentasikan di dalam SOP AP disusun berdasarkan proses bisnis yang telah dipetakan sebelumnya.

Tujuan dari penelitian ini adalah memodelkan dan memetakan proses bisnis pada DPOP Kota Balikpapan yang sesuai dengan Permenpan RB RI Nomor 19 Tahun 2018 dan menyusun SOP AP pada DPOP Kota Balikpapan yang sesuai dengan PERMENPANRB RI Nomor 35 Tahun 2012. Sehingga pada penelitian ini dilakukan pemetaan proses bisnis dan penyusunan dokumen SOP AP pada keseluruhan DPOP Kota Balikpapan. Dari hasil pengambilan data berupa wawancara yang telah dilakukan dihasilkan sebanyak 31 proses yang terdiri dari 15 proses lama yang dievaluasi menggunakan value-addedd analysis sehingga menghasilkan to-be process dan 16 proses baru yang belum pernah dimodelkan ataupun didokumentasikan. Dengan metode yang digunakan adalah berdasarkan PERMENPAN RB RI Nomor 19 Tahun 2018 dan PERMENPAN RB RI Nomor 35 Tahun 2012 serta notasi yang digunakan dalam proses bisnis mangacu pada Business Process Model Notation (BPMN) dan notasi yang digunakan pada SOP AP adalah flowcharts. Di mana dalam pengumpulan datanya dilakukan berdasarkan wawancara dan studi literatur terhadap penelitian terkait serta dokumen SOP AP yang telah ada. Sehingga, dari penelitian ini dihasilkan dokumen proses bisnis dan dokumen SOP AP.

\section{Metode Penelitian}

Secara garis besar penelitian ini dilaksanakan dalam beberapa tahap, yaitu identifikasi masalah, studi literatur, penilaian kebutuhan SOP, serta perencanaan dan persiapan pemetaan proses bisnis yang berjalan bersamaan, pengembangan proses bisnis, verifikasi proses bisnis, pengembangan SOP AP, verifikasi SOP AP, dan pengesahan SOP AP serta penarikan kesimpulan dan saran. Penelitian ini dilakukan di lingkungan DPOP Kota Balikpapan.

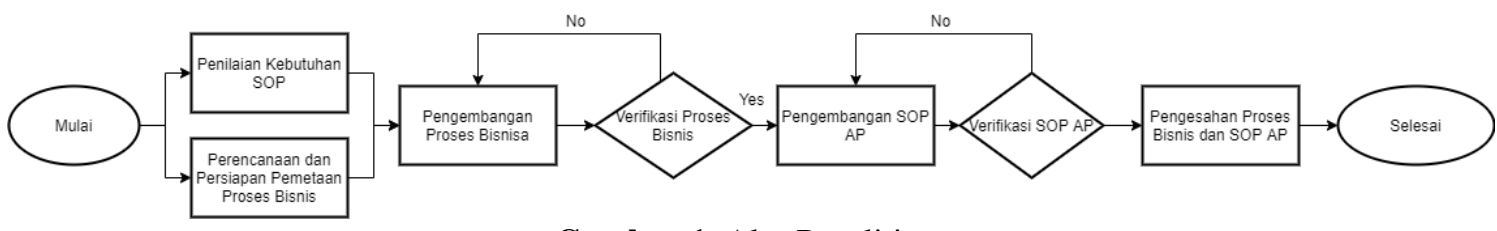

Gambar 1. Alur Penelitian

\subsection{Penilaian Kebutuhan SOP}

Tahapan penilaian kebutuhan SOP dilakukan untuk mengidentifikasi kebutuhan SOP AP yang dibutuhkan. Pada DPOP Kota Balikpapan, tahap ini dilakukan dengan melakukan analisis pada dokumen SOP AP yang telah ada dan menganalisis perubahan apa yang dibutuhkan. Sehingga dihasilkan as-is process dan daftar SOP yang akan dibuat.

\subsection{Perencanaan dan Persiapan Pemetaan Proses Bisnis}

Tahapan selanjutnya adalah melakukan persiapan dan perencanaan pemetaan proses bisnis. Yang dilakukan pada tahapan ini adalah analisis dokumen-dokumen, seperti rencana kerja jangka panjang, rencana kerja tahunan, visi, misi, tujuan dan sasaran instansi pemerintah agar didapat proses-proses bisnis apa yang dibutuhkan untuk menunjang tujuan dan fungsi dari instansi terkait. Pengumpulan informasi juga dilakukan dengan wawancara dengan penanggung jawab dan melalui rencana strategis, laporan kinerja, tugas dan fungsi organisasi. Pada tahap ini hasil yang diharapkan adalah berupa daftar proses bisnis apa yang diperlukan untuk dibuat.

\subsection{Pengembangan Proses Bisnis}

Pada tahapan pengembangan proses bisnis yang dilakukan adalah menyusun peta proses bisnis. Selain itu juga dilakukan analisis terhadap as-is process yang didapat dari SOP terdahulu dengan menggunakan metode kualitatif berupa value-added analysis agar dapat mengetahui 
proses apa yang diperlukan dalam pelaksanaan proses bisnis dan langkah apa yang tidak perlu dalam prosesnya. Value-added analysis sendiri adalah sebuah teknik untuk mengidentifikasi langkah pada sebuah proses dalam penilaian untuk menghilangkannya [10]. Untuk memudahkan peta proses bisnis, maka peta proses bisnis dikategorikan ke dalam beberapa tingkatan atau level. Pada umumnya tingkatan proses bisnis terdiri dari level 0 , level 1 , sampai dengan level ke-n. Luaran dari proses ini adalah to-be process yang nantinya akan digunakan pada DPOP Kota Balikpapan dan menjadi acuan dalam penyusunan SOP AP.

\subsection{Verifikasi Proses Bisnis}

Pada tahapan verifikasi dilakukan pengecekan pada dokumen proses bisnis yang telah dipetakan dan dibuat terhadap process owner dalam hal ini akan dilakukan oleh kepala bidang dan/atau kepala seksi yang melakukan proses-proses tersebut. Apabila pada tahap ini terdapat proses bisnis yang belum sesuai maka akan dilakukan perbaikan. Namun, apabila sudah benar proses selanjutnya dapat dilakukan.

\subsection{Pengembangan SOP AP}

Pada tahapan ini dilakukan penulisan SOP AP. SOP AP yang ditulis disesuaikan dengan proses bisnis yang telah dibuat di proses sebelumnya serta harus memenuhi kebutuhan SOP AP yang telah dianalisis pada proses-proses sebelumnya. Dari proses ini akan dihasilkan suatu dokumen SOP AP yang mencakup proses-proses yang dijalankan pada DPOP Kota Balikpapan.

\subsection{Verifikasi SOP AP}

Pada tahap ini dilakukan verifikasi terhadap dokumen SOP AP yang telah dikembangkan. Verifikasi dilakukan langsung oleh process owner yang bertanggung jawab atas proses yang dijalankan. Apabila terdapat hal yang harus diperbaiki, maka akan dilakukan perbaikan. Apabila menurut process owner SOP AP telah sesuai, maka perbaikan tidak perlu dilakukan.

\subsection{Pengesahan SOP AP}

Pada tahap ini, SOP AP yang telah diverifikasi disahkan oleh Kepala DPOP Kota Balikpapan agar kemudian dapat dijalan dan diterapkan oleh pegawai DPOP Kota Balikpapan sebagai acuan dalam menjalankan tugas pokok dan fungsinya.

\section{Hasil dan Pembahasan}

\subsection{Penilaian Kebutuhan SOP AP}

Penilaian kebutuhan SOP AP dilakukan dengan cara wawancara terhadap process owner dalam hal ini adalah Kepala Bidang, Seksi, Staff, dan Kepala Subbagian yang ada pada DPOP Kota Balikpapan. Selain itu, juga dilakukan analisis terhadap dokumen SOP AP yang telah ada untuk mengetahui lebih detail proses-proses apa saja yang sebelumnya terdapat pada masing-masing bidang. Tabel 1. merupakan hasil dari wawancara yang telah dilakukan.

Tabel 1. Penilaian Kebutuhan SOP AP

\begin{tabular}{llll}
\hline Bidang & No. & \multicolumn{1}{c}{ Prosedur } & \multicolumn{1}{c}{$\begin{array}{c}\text { Prioritas } \\
\text { Kebutuhan }\end{array}$} \\
\hline Sekretariat & 1 & Surat Keluar & Sangat Penting \\
\hline Sekretariat & 2 & Surat Masuk & Sangat Penting \\
\hline Sekretariat & 3 & Penyusunan LKJIP & Penting \\
\hline Sekretariat & 4 & Kenaikan Pangkat & Penting \\
\hline Sekretariat & 5 & Kenaikan Gaji Berkala & Penting \\
\hline Sekretariat & 6 & Kenaikan Gaji Berkala (Selain Kepala Dinas) & Penting \\
\hline Sekretariat & 7 & Penyediaan Barang dan Jasa Oleh Penyedia & Sangat Penting \\
\hline Sekretariat & 8 & Penyelenggaraan Rapat & Sangat Penting \\
\hline Sekretariat & 9 & Penyusunan Rencana Strategis & Sangat Penting \\
\hline Pemuda & 10 & Pelaksanaan Kegiatan Paskibraka Kota Balikpapan & Sangat Penting \\
\hline
\end{tabular}


Samuel Govery, Prosedur Proses Bisnis dan SOP....

\begin{tabular}{|c|c|c|c|}
\hline Pemuda & 11 & Peringatan Sumpah Pemuda & Sangat Penting \\
\hline Pemuda & 12 & Pelaksanaan Pemilihan Pemuda Pelopor & Sangat Penting \\
\hline Pemuda & 13 & Sosialisasi Kewirausahaan Pemuda & Sangat Penting \\
\hline Pemuda & 14 & Pelaksanaan Bakti Sosial Pemuda & Sangat Penting \\
\hline Pemuda & 15 & Pemberian Bantuan Wirausaha Muda & Sangat Penting \\
\hline Pemuda & 16 & Pelatihan Kepemimpinan Berorganisasi & Sangat Penting \\
\hline Pemuda & 17 & Pemilihan Duta Pemuda & Sangat Penting \\
\hline Olahraga & 18 & $\begin{array}{l}\text { Pemberian Penghargaan Bagi Atlet dan Pelatih Olahraga } \\
\text { yang Berprestasi }\end{array}$ & Sangat Penting \\
\hline Olahraga & 19 & Izin Kegiatan di Sarana Prasarana Olahraga & Sangat Penting \\
\hline Olahraga & 20 & Hibah Kepada Lembaga Mitra Olahraga & Sangat Penting \\
\hline Pariwisata & 21 & $\begin{array}{l}\text { Penyusunan Rencana Kebutuhan Sarana Prasarana } \\
\text { Pariwisata }\end{array}$ & Sangat Penting \\
\hline Pariwisata & 22 & $\begin{array}{l}\text { Pemantauan dan Evaluasi Pengelolaan Sarana Prasarana } \\
\text { Pariwisata dalam Rangka Pengembangan Destinasi } \\
\text { Pariwisata Pantai Manggar Segara Sari }\end{array}$ & Sangat Penting \\
\hline Pariwisata & 23 & Penanganan Pengaduan Masyarakat & Sangat Penting \\
\hline Pariwisata & 24 & Peninjauan Tanda Daftar Usaha Pariwisata (TDUP) & Sangat Penting \\
\hline Pariwisata & 25 & Pengawasan Jasa Usaha Pariwisata Kota Balikpapan & Sangat Penting \\
\hline Pariwisata & 26 & Pengumpulan Data Kunjungan Wisatawan & Sangat Penting \\
\hline Pariwisata & 27 & Pengumpulan Data Usaha Pariwisata Kota Balikpapan & Sangat Penting \\
\hline Pariwisata & 28 & Operasional Balikpapan Tourism Board & Sangat Penting \\
\hline Pariwisata & 29 & Pelakasanaan Pemilihan Duta Wisata Manuntung & Sangat Penting \\
\hline Pariwisata & 30 & $\begin{array}{l}\text { Pelaksanaan Promosi Pariwisata di Dalam dan Luar } \\
\text { Negeri }\end{array}$ & Sangat Penting \\
\hline Pariwisata & 31 & Operasional TIC (Tourism Information Center) Bandara & Sangat Penting \\
\hline
\end{tabular}

Tabel 1 didapatkan dari wawancara yang dilakukan kepada stakeholders terkait, seperti Kepala Bidang, Kepala Subbagian, Kepala Seksi dan Staff Seksi. Dari hasil wawancara dan analisis terhadap dokumen SOP AP yang ada maka diperoleh 31 proses yang akan dimodelkan pada penelitian ini. Di mana, untuk sekretariat terdapat 9 kegiatan, bidang pemuda terdapat 8 kegiatan, bidang olahraga terdapat 3 kegiatan, dan bidang pariwisata terdapat 11 kegiatan. Dari semua kegiatan yang terdapat pada penilaian kebutuhan, semuanya memiliki prioritas kebutuhan yang sangat penting dan penting. Prioritas kebutuhan ini didapat dengan wawancara kepada process owner. Dimana menurut process owner, proses-proses di atas adalah prosesproses yang menunjang langsung tujuan, visi, misi, dan tupoksi dari setiap entitas yang ada di DPOP Kota Balikpapan, serta seringkali dilaksanakan sehingga memiliki skala kepentingan yang tinggi.

\subsection{Perencanaan dan Persiapan Pemetaan Proses Bisnis}

Pada tahap perencanaan dan persiapan pemetaan proses bisnis ini dilakukan analisis terhadap dokumen rencana strategis yang telah dibuat oleh DPOP Kota Balikpapan. Tahapan ini sendiri dilakukan untuk melihat proses-proses apa saja yang dijalankan pada DPOP Kota Balikpapan yang dapat memenuhi tujuan dan sasaran yang ada. Sehingga, setelah mengetahui perencanaan strategis pada DPOP Kota Balikpapan dan proses-proses didalamnya dapat dipetakan proses-proses yang terdapat pada penilaian kebutuhan SOP AP dan Renstra untuk menentukan proses-proses apa yang nantinya akan dimodelkan ke dalam proses bisnis dan dikomentasikan ke dalam SOP AP.

Untuk menentukan proses bisnis dan SOP AP yang diperlukan oleh DPOP Kota Balikpapan, maka dilakukan pemetaan antara penilaian kebutuhan SOP AP dengan Rencana 
Strategis DPOP Kota Balikpapan. Pemetaan dilakukan dengan melihat proses apa saja yang ada pada penilaian kebutuhan SOP AP dan ada pula di prenencaan strategis.

Dari pemetaan yang dilakukan dapat dilihat bahwa beberapa kegiatan yang ada pada penilaian kebutuhan tidak terdapat pada dokumen resntra DPOP Kota Balikpapan dan sebaliknya. Tidak semua kegiatan yang ada pada renstra muncul pada penilaian kebutuhan yang terdapat pada DPOP Kota Balikpapan. Contohnya adalah proses kenaikan pangkat yang hanya muncul pada penilaian kebutuhan tetapi tidak terdapat pada renstra. Selain itu, proses cetak brosur informasi dan souvenir hanya muncul pada renstra, tetapi tidak terdapat pada penilaian kebutuhan. Hal ini disebabkan karena beberapa proses yang ada pada renstra tidak dijalankan dan dianggap tidak mendesak oleh process owner yang ada pada DPOP Kota Balikpapan. Sedangkan, beberapa proses yang ada pada penilaian kebutuhan dan tidak terdapat pada renstra dikarenakan penyusunan resntra yang dilakukan pada 2016 belum menganggap proses-proses tersebut penting untuk dimasukkan ke dalam renstra. Sehingga, tidak semua kegiatan yang tertuang pada renstra DPOP Kota Balikpapan akan dimodelkan ke dalam proses bisnis dan didokumentasikan pada SOP AP. Dan yang akan dimodelkan ke dalam Proses Bisnis dan didokumentasikan ke dalam SOP AP adalah 31 proses, yang terdiri dari 15 proses lama dan 16 proses baru.

\subsection{Pengembangan Proses Bisnis}

Pada tahapan ini dilakukan pemetaan proses bisnis mulai dari level ke- 0 , level ke-1 dan level ke-2. Level ke-0 mendefinisikan proses paling umum yang ada di DPOP Kota Balikpapan, yaitu proses utama dan pendukung. Level ke-1 mendefinisikan proses-proses yang lebih detail dari level ke-0 di mana terdiri dari subproses-subproses yang menyusun proses pada level-0. Dan level ke-2 mendefinisikan proses-proses yang paling detail yang dijalankan oleh DPOP Kota Balikpapan. Dimana yang akan dimodelkan adalah proses-proses yang ada pada tabel 1 .

Kemudian, digunakan value-added analysis untuk mengevaluasi as-is process yang ada pada DPOP Kota Balikpapan, sehingga akan diperoleh to-be process yang nantinya akan dapat digunakan untuk menggantikan proses lama. To-be process yang dihasilkan terdiri dari 15 proses dan terdapat 16 proses baru, sehingga keseluruhan proses yang akan dimodelkan ke dalam proses bisnis dan SOP AP adalah 31 proses. Salah satu as-is process yang terdapat pada DPOP Kota Balikpapan adalah proses Pembagian Bonus Atlet dan Pelatih.

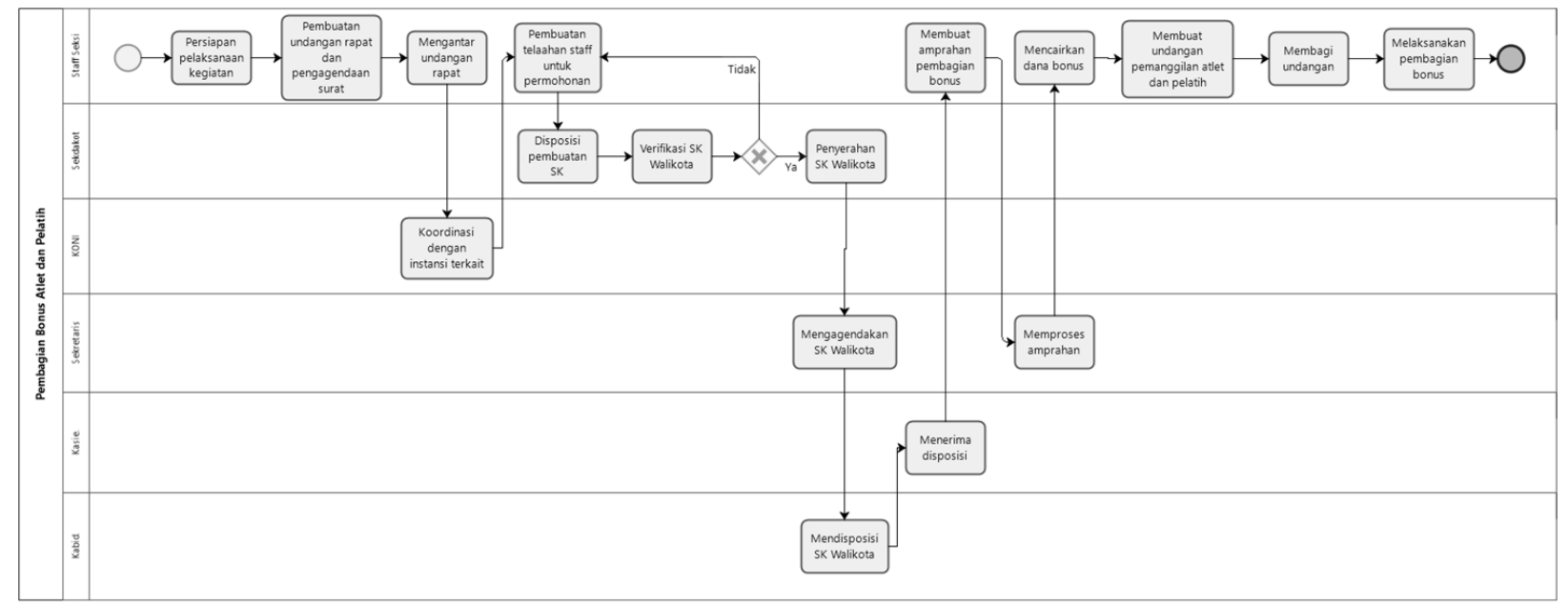

Gambar 2. As-Is Process Pembagian Bonus Atlet dan Pelatih

Dari gambar di atas, kemudian akan dianalisis untuk melihat kegiatan-kegiatan apa yang tidak diperlukan dan tidak menambah nilai pada keluaran dari proses tersebut, kegiatan-kegiatan apa yang mempengaruhi keluaran dari proses tersebut dan kegiatan apa yang dapat menambah keluaran dari proses tersbut. Di mana untuk kegiatan yang tidak menambah nilai maka dapat 
dihilangkan dari proses tersebut. Pada analisis ini dapat dilihat bahwa ada 3 klasifikasi, yaitu VA (Value Added) yang menunjukkan bahwa kegiatan yang dilakukan dalam proses tersebut mempengaruhi hasil dari proses tersebut, NVA (Non-Value Added) yang menunjukkan bahwa kegiatan yang dilakukan tidak mempengaruhi hasil dari proses yang dilakukan sehingga dapat dihapuskan, dan BVA (Business Value Added) yang menunjukkan bahwa kegiatan dapat menambahkan hasil pada proses yang dilakukan secara langsung. Sehingga, dari analisis yang dilakukan pada proses ini dihasilkan 14 langkah termasuk dalam NVA dan 4 langkah termasuk dalam VA. Sehingga, pada langkah yang masuk ke dalam kategori NVA dapat dihilangkan atau diganti dengan langkah yang dibutuhkan saat ini. Hal yang sama juga dilakukan pada 14 proses lainnya dan didapatkan hasil analisis seperti pada tabel 2. Dapat dilihat pada tabel beberapa proses terdiri dari langkah-langkah yang termasuk dalam NVA sehingga dapat dilakukan perbaikan pada langkah-langkah tersebut.

Tabel 2 Hasil Value-Added Analysis

\begin{tabular}{lllll}
\hline No. & \multicolumn{1}{c}{ Nama As-is Process } & NVA & VA & BVA \\
\hline 1. & Surat keluar & 1 & 5 & 0 \\
\hline 2. & Surat masuk & 6 & 3 & 0 \\
\hline 3. & Kenaikan pangkat & 1 & 5 & 1 \\
\hline 4. & Kenaikan gaji berkala & 1 & 4 & 1 \\
\hline 5. & Pelaksanaan kegiatan paskibraka Kota Balikpapan & 6 & 8 & 3 \\
\hline 6. & Pembagian bonus atlit dan pelatih & 14 & 4 & 0 \\
\hline 7. & Retribusi sarana olahraga & 6 & 3 & 1 \\
\hline 8. & Operasional tim lapangan kunjungan penerbitan izin/ rekomendasi & 11 & 3 & 0 \\
& izin usaha kepariwisataan & & & \\
\hline 9. & Inventarisasi dan pengawasan jasa usaha pariwisata Kota Balikpapan & 6 & 2 & 1 \\
\hline 10. & Pengumpulan data kunjungan obyek dan kunjungan wisatawan & 7 & 0 & 0 \\
\hline 11. & Pengumpulan data usaha pariwisata Kota Balikpapan & 3 & 3 & 1 \\
\hline 12. & Operasional Balikpapan Tourism Board & 3 & 9 & 0 \\
\hline 13. & Pelaksanaan pemilihan duta wisata & 6 & 4 & 1 \\
\hline 14. & Pelaksanaan promosi pariwisata di dalam dan luas negeri & 6 & 5 & 1 \\
\hline 15. & Operasional tourism information center & 3 & 6 & 0 \\
\hline
\end{tabular}

Setelah dilakukan analisis kualitatif pada as-is process yang ada pada DPOP Kota Balikpapan, maka dapat dilakukan pemetaan proses bisnis yang baru berupa to-be process. Pemetaan dilakukan dengan dimulai dari level ke-0 yang menggambarkan proses secara umum pada DPOP Kota Balikpapan, dilanjutkan pada level ke-1 yang merupakan penjabaran yang lebih spesifik dari level sebelumnya dan level ke-2 yang merupakan to-be process yang diperoleh dari analisis sebelumnya.

Dari analisis yang dilakukan pada Tabel 2, maka diperoleh to-be process yang dapat dilihat pada gambar 3. Di mana dari yang awalnya proses ini terdiri dari 18 langkah yang 14 langkah didalamnya termasuk ke dalam NVA diperoleh sebuah to-be process yang memiliki 9 langkah. Hal ini didapat dari penghapusan dan pengubahan beberapa proses yang masuk ke dalam kategori NVA. Sebagai contoh adalah persiapan pelaksanaan kegiatan karena langkah ini digantikan menjadi pengajuan usulan, selain itu asistensi/verifikasi surat keputusan yang dilakukan oleh sekretaris kota dihapuskan karena saat ini proses dilakukan tanpa melibatkan pemerintahan kota. Sehingga diperoleh to-be process pada gambar 3. 


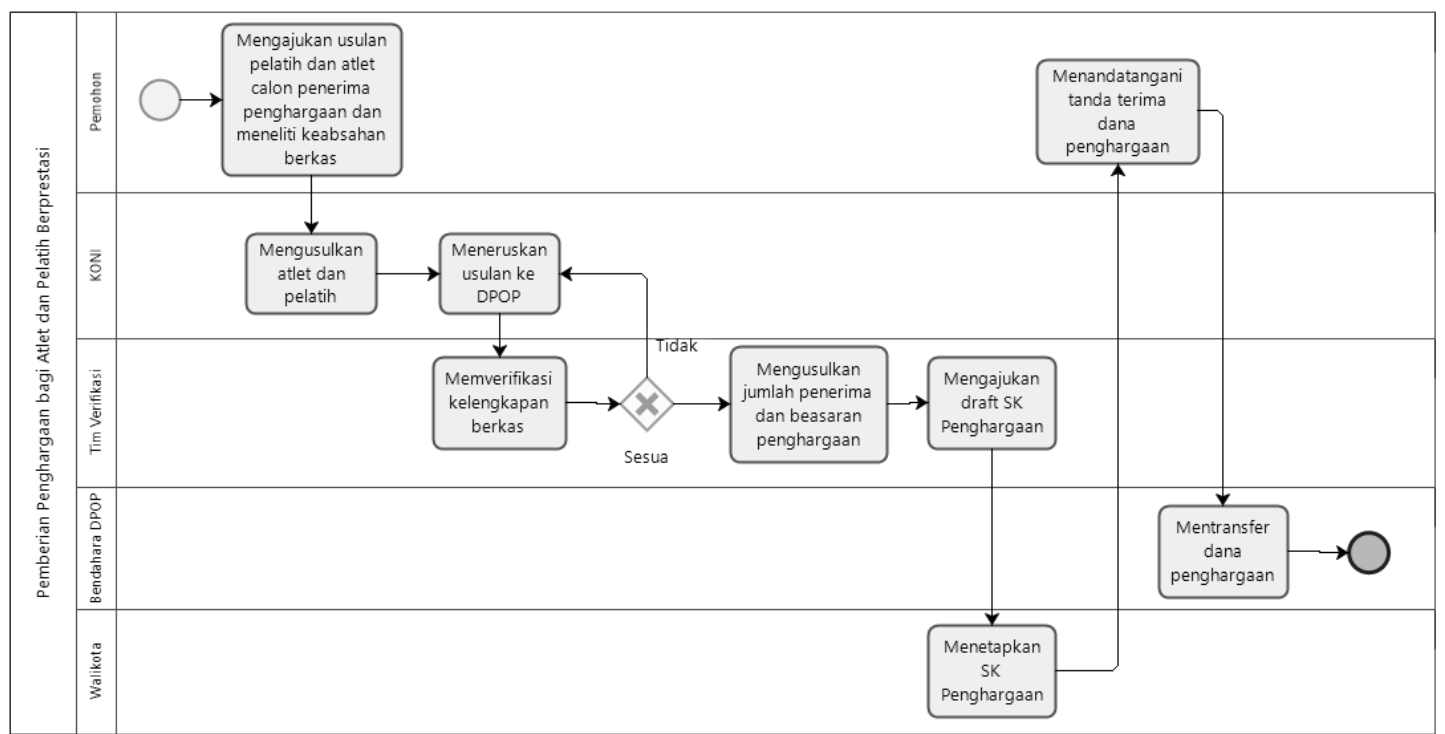

Gambar 3. To-be Process Pemberian Penghargaan bagi Atlet dan Pelatih Berprestasi

\subsection{Verifikasi Proses Bisnis}

Pada tahap ini, proses bisnis yang telah dimodelkan diperiksa oleh process owner kesesuaiannya dengan kebutuhan saat ini. Jika dirasa masih perlu adanya perbaikan, maka proses bisnis yang telah dimodelkan akan diperbaiki kembali. Namun, apabila proses bisnis dirasa sudah sesuai, maka process owner akan menandatangani lembar verifikasi. Pada penelitian ini semua proses yang terdiri dari 31 proses telah diverifikasi oleh process owner dan dapat dilanjutkan ke tahapan berikutnya.

\subsection{Pengembangan SOP AP}

Dari 15 to-be process yang telah dibuat serta 16 proses baru yang diperoleh dan diverifikasi sebelumnya, maka dapat diimplementasikan ke dalam lembar bagian flowchart dokumen SOP AP dengan dilakukan berbagai penyesuaian dengan format SOP AP. Tahapan pengembangan SOP AP dilakukan dengan menyusun SOP AP sesuai dengan aturan yang terdapat pada Permenpan RB RI.

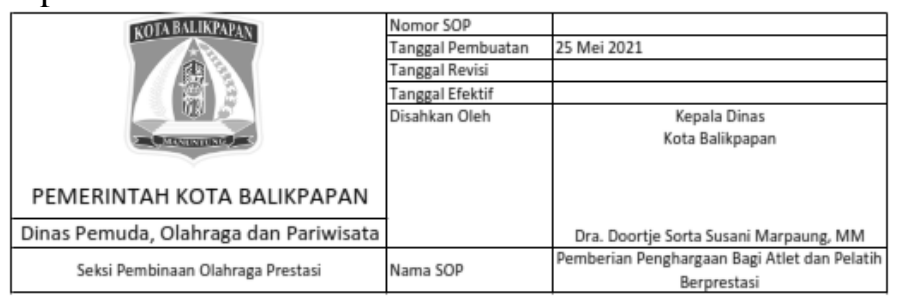

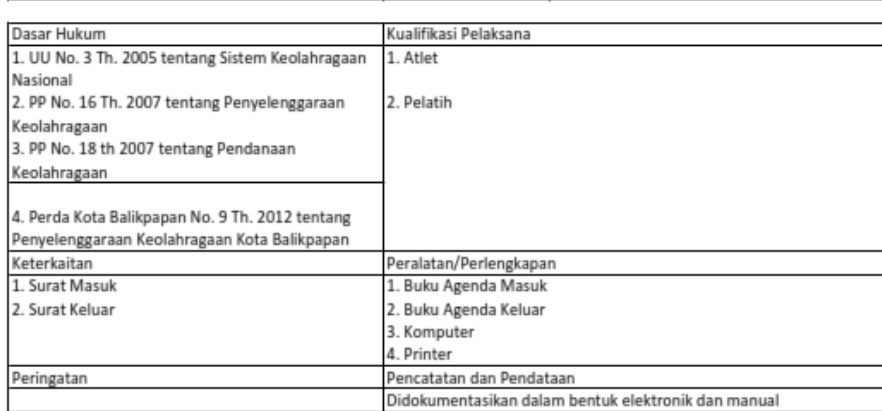

Gambar 4. Lembar Identitas SOP AP Pemberian Penghargaan bagi Atlet dan pelatih Berprestasi 
Gambar 4 menunjukkan lembar identitas dari proses yang telah disusun. Lembar identitas berisikan data-data yang berkaitan dengan SOP tersebut, seperti nomor, judul, dan lainlain.

\begin{tabular}{|c|c|c|c|c|c|c|c|c|c|c|}
\hline \multirow[b]{2}{*}{ No } & \multirow[b]{2}{*}{ Kegiatan } & \multicolumn{5}{|c|}{ Pelaksana } & \multicolumn{2}{|c|}{ Baku Mutu } & \multirow[b]{2}{*}{ Output } & \multirow[b]{2}{*}{ Ket } \\
\hline & & Pemohon & KONI & Tim Verifikasi & Bendahara DPOP & Walikota & $\begin{array}{l}\text { Persyaratan } \\
\text { Kelengkapan }\end{array}$ & Waktu & & \\
\hline 1 & $\begin{array}{l}\text { Mengajukan usulan pelatih dan atlet } \\
\text { calon penerima penghargaan dan } \\
\text { meneliti keabsahan berkas }\end{array}$ & & & & & & \begin{tabular}{|l|} 
KTP, Piagam, Berita \\
Kejuaraan, Sertifikat \\
Pelatih, Buku Rekening, \\
NPWP
\end{tabular} & 1 Hari & $\begin{array}{l}\text { Kelengkapan berkas } \\
\text { persyaratan }\end{array}$ & \\
\hline 2 & Mengusulkan atlet dan pelatih & & $\square$ & & & & Berkas persyaratan & 1 Hari & Berkas persyaratan & \\
\hline 3 & Meneruskan usulan ke DPOP & & 5 & & & & Berkas persyaratan & 1 Hari & Berkas terlegalisir & \\
\hline 4 & Memverifikasi kelengkapan berkas & & Tida & & & & Berkas persyaratan & 15 Menit & $\begin{array}{l}\text { Dokumen pengusul yang } \\
\text { memenuhi syarat }\end{array}$ & \\
\hline 5 & $\begin{array}{l}\text { Mengusulkan jumlah penerima dan } \\
\text { besaran penghargaan }\end{array}$ & & & & & & \begin{tabular}{|l} 
Dokumen pengusul \\
yang memenuhi \\
syarat
\end{tabular} & $1 \mathrm{Jam}$ & TS ke Walikota & \\
\hline 6 & Mengajukan draft SK Penghargaan & & & & & & \begin{tabular}{|l|} 
Jumlah penerima dan \\
besaran penghargaan
\end{tabular} & $1 \mathrm{Jam}$ & Draft Sk Walikota & \\
\hline 7 & Menetapkan SK Penghargaan & & & & & & sk Walikota & $1 \mathrm{Jam}$ & SK Penghargaan & \\
\hline 8 & $\begin{array}{l}\text { Menandatangani tanda terima dana } \\
\text { penghargaan }\end{array}$ & & & & & & $\begin{array}{l}\text { Daftar terima } \\
\text { penghargaan }\end{array}$ & 10 Menit & $\begin{array}{l}\text { Tanda tangan pada daftar } \\
\text { terima penghargaan }\end{array}$ & \\
\hline 9 & Mentransfer dana penghargaan & & & & $\longrightarrow \longrightarrow$ & & Tanda terima & 1 Hari & Bukti transfer & \\
\hline
\end{tabular}

Gambar 5. Diagram Alir SOP AP Pemberian Penghargaan bagi Atlet dan Pelatih Berprestasi

Pada gambar 5 dapat dilihat alur dari proses yang ada pada SOP. Lembar ini terdiri kegiatan, pelaksana, baku mutu, dan lain-lain.

\subsection{Verifikasi SOP AP}

Dokumen SOP AP yang telah dibuat, diperika oleh masing-masing process owner untuk melihat apakah ada kekeliruan dalam penyusunannya, seperti kesalahan penulisan pada proses, process owner, dan format flowchart yang ada pada panduan Permenpan RB RI No. 35 Tahun 2012. Jika terdapat kekeliruan maka akan dilakukan perbaikan, jika tidak maka process owner menandatangani lembar verifikasi. Dari proses ini dihasilkan lembar verifikasi berupa tabel yang berisikan bahwa semua proses yang telah disusun ke dalam SOP telah diverifikasi dan dapat untuk disahkan.

\subsection{Pengesahan SOP AP}

Dari SOP AP yang telah diverifikasi oleh masing-masing process owner pada langkah sebelumnya, dokumen SOP AP diberikan kepada Kepala DPOP untuk kemudian ditandatangani dan disahkan agar kemudian dapat digunakan oleh DPOP Kota Balikpapan. Tanda tangan oleh Kepala DPOP Kota Balikpapan dimasukkan ke dalam lembar identitas pada masing-masing proses dan setelahnya subbagian umum akan memberikan nomor serta stempel pada dokumen SOP 


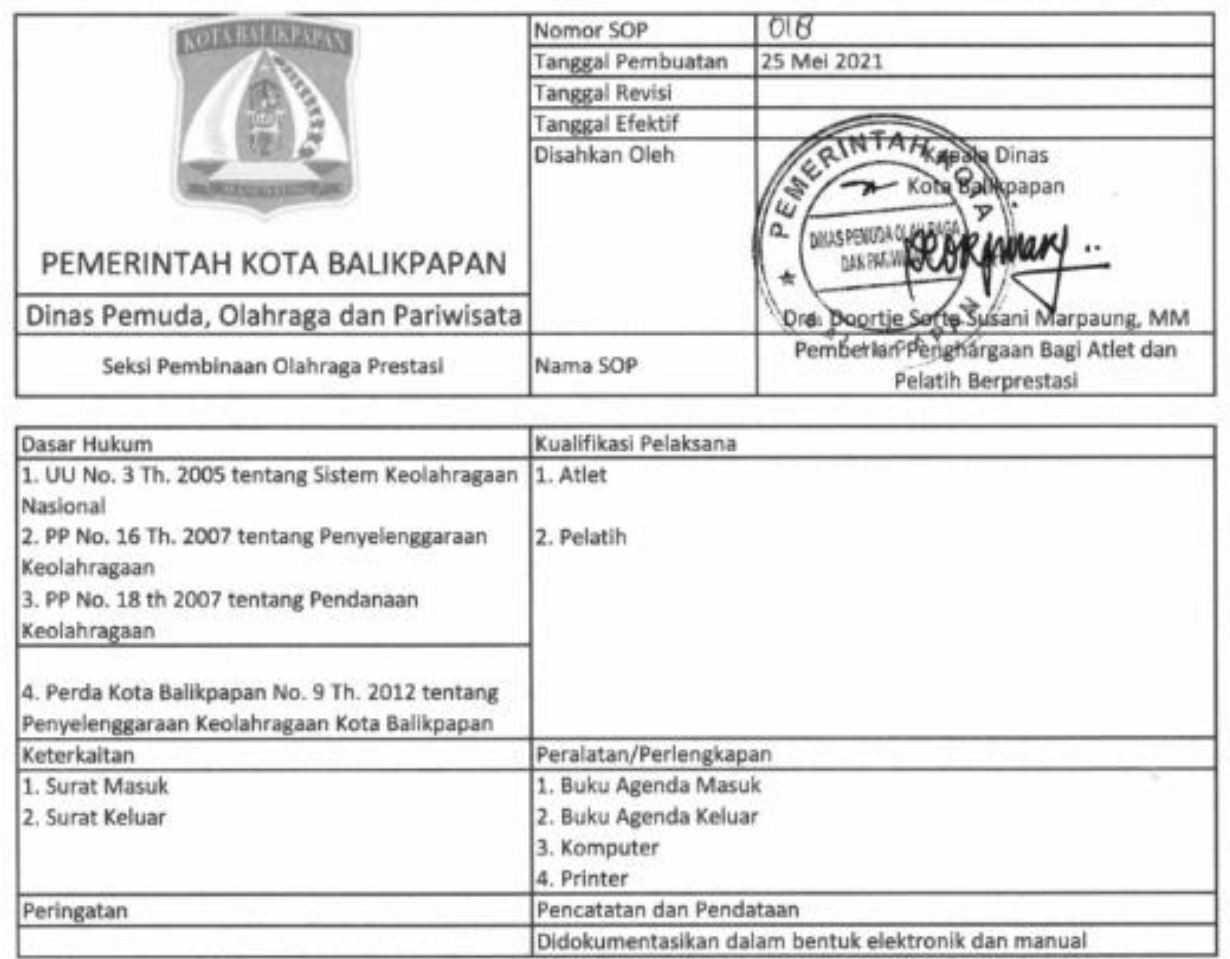

Gambar 6. Lembar Identitas SOP AP yang Telah Disahkan

Gambar 6 menunjukkan SOP yang telah disahkan, di mana pada lembar identitasnya diberikan nomor SOP, kemudian Kepala DPOP Kota Balikpapan menandatangani lembar identitas tersebut dan diberikan stempel DPOP Kota Balikpapan. Hal yang sama juga dilakukan pada 30 proses lainnya yang telah diverifikasi.

\section{Kesimpulan dan Saran}

Kesimpulan yang diperoleh dari hasil penelitian ini adalah terdapat 15 as-is process pada DPOP Kota Balikpapan yang kemudian dianalisis menggunakan value-added analysis dan dimodelkan ke dalam to-be process. Kemudian terdapat 16 proses baru yang sebelumnya belum dimodelkan. Sehingga, ada total 31 proses yang dimodelkan dan diverifikasi oleh process owner sesuai dengan Permanpan RB RI Nomor 19 Tahun 2018. Selanjutnya, terdapat 31 proses yang didokumentasikan, diverifikasi oleh process owner, dan disahkan ke dalam dokumen SOP AP oleh Kepala DPOP Kota Balikpapan sesuai dengan aturan yang ada pada Permenpan RB RI Nomor 35 Tahun 2012.

Saran yang dapat diberikan dari hasil penelitian ini adalah dikarenakan penelitian ini dilakukan dalam ruang lingkup proses pada DPOP Kota Balikpapan, diharapkan pada penelitian selanjutnya dapat dilakukan perbaikan pada proses-proses yang ada saat ini, sehingga dapat diperoleh proses yang lebih baik lagi. Serta perlu diberikan sosialisasi pemahaman akan SOP AP dan proses bisnis kepada setiap entitas di DPOP Kota Balikpapan agar proses yang dijalan dapat terlaksana dengan baik.

\section{Daftar Pustaka}

[1] A. Chandra e Y. Hadi, "Analisis dan Rekayasa Proses Bisnis pada bagian Layanan Akademik di Sekretariat Fakultas Sains dan Teknologi Universitas Ma Chung," Jurnal Teknik Industri, pp. 161$170,2017$. 
[2] L. Hasiara, Sudarlan e A. M. Diah, "Standar Operasional Prosedur Sebagai Media Pencapaian Pendapatan Wajar Tanpa Pengecualian (WTP) di Organisasi Pemerintah Daerah," Prosiding Seminar Nasional Penelitian \& Pengabdian Kepada Masyarakat, pp. 84-89, 2019.

[3] KEMENPANRB RI, Peraturan Menteri Pnedayagunaan Aparatur Negara dan Reformasi Birokrasi RI Nomor 35 Tahun 2012, Jakarta: Kementerian Pendayagunaan Aparatur Negara dan Reformasi Birokrasi Republik Indonesia, 2012.

[4] KEMENPANRB RI, Peraturan Menteri Pendayagunaan Aparatur Negara dan Reformasi Birokrasi Republik Indonesia Nomor 19 Tahun 2018, Jakarta: Kementerian Pendayagunaan Aparatur Negara dan Reformasi Birokrasi Republik Indonesia, 2018.

[5] H. H. Sutrisno, Permodelan Proses Bisnis dan Penyusunan Standard Operating Procedure (Studi Kasus: Badan Pengelola Pajak Daerah dan Retribusi Daerah Kota Balikpapan, Balikpapan: Institut Teknologi Kalimantan, 2020.

[6] D. Dewantari, Analisis dan Pemodelan Proses Bisnis Pemenuhan Pesanan UMKM XYZ, Surabaya: ITS, 2018.

[7] R. Yunitarini e F. H. R, "Pemodelan Proses Bisnis Akademik Teknik Informatika Universita Trunojoyo dengan Business Process Modelling Notation (BPMN)," Jurnal Simantec, 2016.

[8] Zakiah, Pemodelan Proses Bisnis dan Penyusunan Standard Operating Procedure (SOP) pada Dinas Pendidikan dan Kebudayaan Kota Balikpapan, Balikpapan: ITK, 2020.

[9] N. Kurniawati, Pemodelan Proses Bisnis dan Penyusunan SOP Manajemen Kerjasama dan Beasiswa (Studi Kasus: Institut Teknolgi Kalimantan, Balikpapan: ITK, 2020.

[10] M. Dumas, M. Rosa, J. Mending e H. Reijers, Funamentals of Business Process management Second Edition, Berlin: Springer, 2018.

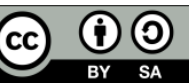

is licensed under a Creative Commons Attribution International (CC BY-SA 4.0) 